\title{
Hypertension and Dementia in the Elderly: The Leisure World Cohort Study
}

\author{
Annlia Paganini-Hill1,2 \\ ${ }^{1}$ Department of Preventive Medicine, Keck School of Medicine, University of Southern California, \\ Los Angeles, CA 90033, USA \\ ${ }^{2}$ Department of Neurology University of California, Irvine CA 92697, USA
}

Correspondence should be addressed to Annlia Paganini-Hill, annliahi@usc.edu

Received 29 June 2011; Accepted 4 October 2011

Academic Editor: Blas Gil Extremera

Copyright ( $) 2012$ Annlia Paganini-Hill. This is an open access article distributed under the Creative Commons Attribution License, which permits unrestricted use, distribution, and reproduction in any medium, provided the original work is properly cited.

Recent studies have highlighted the deleterious role of cardiovascular risk factors, including hypertension, on the incidence of dementia. Although midlife hypertension is associated with later development of dementia, the role of late-life hypertension remains unclear. We explored the association of hypertension and its treatment with incident dementia in 13978 older ( median $=74$ years) adults followed from 1981 to 2010 (median $=13$ years) and calculated risk estimates using Cox regression analysis in two age groups ( $<75$ and $75+$ years) in men and women separately. Dementia status was determined from inperson evaluations, followup questionnaires, hospital data, and death certificates. In the older women, current users of blood pressure medication at baseline had a $26 \%$ increased risk of dementia (95\% CI 1.06-1.51). In the younger men, those with untreated hypertension and those with past use of blood pressure medication use had about a 30\% nonsignificant increased risk of dementia. High blood pressure and its treatment appear to have different effects in men and women and in the old and older.

\section{Introduction}

As a result of an aging population, the prevalence of dementia, which in 2005 affected 24.3 million people worldwide, is expected to afflict more than 81 million by 2040 [1]. Recent studies have highlighted the deleterious role of cardiovascular risk factors, including hypertension, on the incidence of dementia and suggested that their therapeutic control may reduce risk of development of dementia in later life $[2,3]$. Several longitudinal studies have found midlife hypertension to be related to dementia (reviewed in $[3,4]$ ), but the role of late-life hypertension remains unclear.

The focus of the present study was to examine the possible role of hypertension and its treatment as predictors of dementia in elderly men and women. We report here the results in a large cohort (nearly 14000) of elderly (median age 74 years) men and women followed for up to 29 years (median 13 years).

\section{Methods}

The Leisure World Cohort Study was established in the early 1980s when 13978 residents of a California retirement community (Leisure World Laguna Hills) completed a postal health survey. Residents were recruited in four waves: those who owned homes in Leisure World on June 1, 1981; new residents who had moved into the community and were living there on June 1,1982; on June 1, 1983; on October 1, 1985. The baseline survey asked demographic information, brief medical history, medication use, and personal habits including cigarette smoking, exercise, alcohol consumption, and beverage intake. The subjects were asked if a doctor ever told them they had high blood pressure and if they had ever taken or were currently taking specific medications including "Reserpine (please include Raudixin, Ser-Ap-Es, Hydropres, Rauwolfias, Metatensin)" and "other blood pressure medication, water pills." The population and 
the cohort are mostly Caucasian, well educated, uppermiddle class, and elderly.

Followup of the cohort is maintained by periodic resurvey $(1983,1985,1992,1998)$, review of local hospital discharge data (1981-2001), and determination of vital status by search of governmental and commercial death indexes and ascertainment of death certificates. The 1983 followup questionnaire asked new diagnoses of high blood pressure since the baseline survey. The 1998 questionnaire again asked if the subject had ever been told by a doctor that they had high blood pressure and the frequency of use of high blood pressure medication.

Dementia cases were identified from in-person evaluations as part of a dementia study [5], hospital records, death certificates, and/or followup questionnaires with the date of diagnosis being the date at which dementia was first mentioned. Participants were followed to dementia diagnosis, death or December 31, 2010, whichever came first. To date 37 cohort members have been lost to followup; search of death indices did not reveal that these individuals were deceased.

Chi-square tests were used for comparison of categorical variables and $t$-tests for testing differences in means of continuous variables. Age-adjusted hazard ratios (HRs) of dementia associated with hypertension were estimated using Cox proportional hazard regression analysis with age at study entry being the age when the baseline survey was completed and the event of interest being age at dementia. Separate analyses were done for two age groups: $<75$ years and $75+$ years of age at baseline, with additional adjustment for age (continuous). Because women differ from men on many variables, women live longer on average than men, and for comparison with other studies limited to one sex, we performed separate analyses for men and women. Statistical analyses were performed using SAS version 9.2 (SAS Institute Inc., Cary, NC). No adjustment in the $P$ values was made for multiple comparisons.

Previous reports present details of the methods and the reliability of recall of the self-reported information [69]. The Institutional Review Boards of the University of Southern California and the University of California, Irvine approved the study.

\section{Results}

At study entry, the participants' mean and median age was 74 years (standard deviation $=7$ ). By December 31, 2010, 2429 participants had been diagnosed with dementia and 13134 had died. Age at dementia ranged from 66 to 106 years (median, 90 years). Dementia cases were identified by The $90+$ Study $(n=690)$, hospitalization record $(n=199)$, followup questionnaire $(n=264)$, and death certification ( $n=1768)$; these categories are not mutually exclusive.

Characteristics of the study participants are shown in Table 1 . Women differed significantly from men on all these variables $(P<0.001$ for all variables except cancer where $P<0.02)$.

Tables 2 and 3 show the age-adjusted HRs of incident dementia for hypertension and its treatment for women and
TABLE 1: Characteristics of participants by sex, The Leisure World Cohort.

\begin{tabular}{|c|c|c|c|c|}
\hline \multirow{3}{*}{ Number } & \multirow{2}{*}{\multicolumn{2}{|c|}{$\begin{array}{l}\text { Men } \\
5101\end{array}$}} & \multirow{2}{*}{\multicolumn{2}{|c|}{$\begin{array}{c}\text { Women } \\
8877\end{array}$}} \\
\hline & & & & \\
\hline & Mean & SD & Mean & SD \\
\hline Age at baseline (years) & 74 & 7.2 & 73 & 7.4 \\
\hline Age at last followup (years) & 86 & 7.0 & 88 & 7.0 \\
\hline Followup years & 11 & 7.3 & 15 & 7.7 \\
\hline Active activities (hrs/day) & 1.1 & 1.3 & 0.9 & 1.1 \\
\hline Other less strenuous activities (hrs/day) & 3.6 & 2.7 & 4.4 & 2.6 \\
\hline Alcohol (drinks/day) & 1.6 & 1.5 & 1.2 & 1.2 \\
\hline Caffeine (mg/day) & 176 & 172 & 168 & 166 \\
\hline \multirow[t]{2}{*}{ Body mass index $\left(\mathrm{kg} / \mathrm{m}^{2}\right)$} & 24 & 2.9 & 23 & 3.5 \\
\hline & No. & $\%$ & No. & $\%$ \\
\hline \multicolumn{5}{|l|}{ Medical history } \\
\hline High blood pressure & 1843 & 36 & 3620 & 41 \\
\hline Angina & 738 & 14 & 839 & 9 \\
\hline Heart attack & 847 & 17 & 588 & 7 \\
\hline Stroke & 370 & 7 & 333 & 4 \\
\hline Cancer & 826 & 16 & 1574 & 18 \\
\hline Diabetes & 425 & 8 & 442 & 5 \\
\hline Rheumatoid arthritis & 226 & 4 & 608 & 7 \\
\hline \multicolumn{5}{|l|}{ Smoke } \\
\hline Never & 1708 & 33 & 4883 & 55 \\
\hline Past & 2953 & 58 & 2880 & 32 \\
\hline Current & 437 & 9 & 1106 & 12 \\
\hline Deceased by December 31, 2010 & 4930 & 97 & 8204 & 92 \\
\hline
\end{tabular}

men, respectively. Forty-three percent of subjects reported not having high blood pressure and not taking hypertensive medication. Of the remaining with high blood pressure, about $21 \%$ took no medication, $18 \%$ took medication in the past but not currently, and $18 \%$ were currently taking blood pressure medication. The only significant risk factor for dementia was current blood pressure medication $(\mathrm{HR}=$ $1.26,95 \%$ CI 1.06-1.51) in women aged 75+ years. No effect of current treatment was seen in men. The greatest (though nonsignificant) risks in men were found among men less than 75 years old with untreated hypertension $(\mathrm{HR}=1.27$, 95\% CI 0.95-1.70) and with past use of blood pressure medication $(\mathrm{HR}=1.33,95 \%$ CI 1.00-1.79).

Followup questionnaires identified few additional individuals with hypertension. Of the 9731 who returned the 1983 followup survey, 188 (2\%) reported a new diagnosis of high blood pressure. In 1998, 219 (11\%) of 1963 who returned the questionnaire reported having high blood pressure in 1998 but not at baseline.

\section{Discussion}

In recent years the strict division between Alzheimer's disease and vascular dementia has faded with advancing research in neuropathology, neuroradiology, and epidemiology. Most dementia patients, irrespective of their clinical diagnosis, 
TABLe 2: Hazard ratios for dementia by hypertension and its treatment in men, Leisure World Cohort Study, 1981-2010.

\begin{tabular}{|c|c|c|c|c|c|c|c|c|}
\hline & \multicolumn{4}{|c|}{ Aged $<75$ years } & \multicolumn{4}{|c|}{$75+$ years } \\
\hline & No. & No. with dementia & $\mathrm{HR}$ & $95 \% \mathrm{CI}$ & No. & No. with dementia & HR & $95 \% \mathrm{CI}$ \\
\hline \multicolumn{9}{|l|}{ Hypertension and treatment } \\
\hline No hypertension and no treatment & 1160 & 153 & 1.00 & & 1171 & 163 & 1.00 & \\
\hline Hypertension but no treatment & 495 & 66 & 1.27 & $0.95-1.70$ & 480 & 51 & 1.02 & $0.75-1.41$ \\
\hline Past treatment & 449 & 64 & 1.33 & $1.00-1.79$ & 384 & 42 & 0.92 & $0.66-1.30$ \\
\hline Current treatment & 430 & 42 & 1.00 & $0.71-1.41$ & 532 & 56 & 1.01 & $0.74-1.37$ \\
\hline \multicolumn{9}{|l|}{ Current hypertensive medication } \\
\hline No & 2104 & 283 & 1.00 & & 2035 & 256 & 1.00 & \\
\hline Yes & 430 & 42 & 0.89 & $0.64-1.24$ & 532 & 56 & 1.02 & $0.76-1.36$ \\
\hline
\end{tabular}

TABLE 3: Hazard ratios for dementia by hypertension and its treatment in women, Leisure World Cohort Study, $1981-2010$.

\begin{tabular}{|c|c|c|c|c|c|c|c|c|}
\hline & \multicolumn{4}{|c|}{ Aged $<75$ years } & \multicolumn{4}{|c|}{$75+$ years } \\
\hline & No. & No. with dementia & HR & $95 \% \mathrm{CI}$ & No. & No. with dementia & $\mathrm{HR}$ & $95 \% \mathrm{CI}$ \\
\hline \multicolumn{9}{|l|}{ Hypertension and treatment } \\
\hline No hypertension and no treatment & 2131 & 479 & 1.00 & & 1522 & 345 & 1.00 & \\
\hline Hypertension but no treatment & 1054 & 177 & 0.88 & $0.74-1.05$ & 937 & 155 & 0.91 & $0.76-1.11$ \\
\hline Past treatment & 1011 & 202 & 0.90 & $0.77-1.06$ & 685 & 137 & 0.92 & $0.75-1.12$ \\
\hline Current treatment & 750 & 148 & 0.99 & $0.82-1.19$ & 787 & 149 & 1.21 & $1.00-1.47$ \\
\hline \multicolumn{9}{|l|}{ Current hypertensive medication } \\
\hline No & 4196 & 858 & 1.00 & & 3144 & 637 & 1.00 & \\
\hline Yes & 750 & 148 & 1.04 & $0.87-1.24$ & 787 & 149 & 1.26 & $1.06-1.51$ \\
\hline
\end{tabular}

have mixed pathology (Alzheimer's changes and cerebrovascular lesions) at autopsy [10, 11]. High blood pressure has long been understood to cause stroke, a risk factor for vascular dementia. However, the association between blood pressure and dementia is complex. Midlife hypertension increases risk of cognitive impairment, Alzheimer's disease, and dementia (reviewed in $[3,4]$ ).

Associations in longitudinal studies of late-life hypertension and dementia have been less consistent. Some found blood pressure levels were higher in individuals who developed dementia [12], Alzheimer's disease [13], or vascular dementia [14] than in those who did not. In the Swedish Longitudinal Population Study of 382 participants (aged 70 years) subjects who developed dementia had significantly higher systolic and diastolic blood pressures about 10 to 15 years before cognitive assessment than subjects without dementia [12]. In the Kungsholmen Project, a communitybased cohort of 1270 participants (aged $\geq 75$ years) in Sweden followed for 6 years, 339 subjects were diagnosed with dementia [13]. Subjects with high SBP $(>180 \mathrm{mmHg})$ had a risk of $1.6(95 \%$ CI 1.1-2.2) for dementia. High DBP $(>90 \mathrm{mmHg})$ was not associated with increased risk. In Hisayama Study, Japan, in which 828 people (aged 6598 years) were followed for 7 years, blood pressure was not related to $\mathrm{AD}$ but 1 standard deviation increase in SBP increased risk of vascular dementia 60\% (95\% CI 1.2 2.2) [14]. The Adult Changes in Thought Study included 2356 participants aged $\geq 65$ years followed for 8 years during which time 380 developed dementia [15]. Only in the youngest age group (65-74 years) did those with high SBP $(\geq 160 \mathrm{mmHg})$ have a significantly increased risk of dementia (HR 1.6, 95\% CI 1.01-2.55) and the risk declined with advancing age to 0.64 (95\% CI $0.32-1.30)$ in the oldest age group ( $>85$ years). In the Women's Memory Study blood pressure levels measured 5 and 9 years before dementia assessment did not differ significantly between demented and nondemented [16]. Others have observed that history of hypertension was not related to dementia [17, 18], Alzheimer's disease [19-22] but was related to vascular dementia [22]. Interestingly, in the Canadian Study of Health and Aging, the presence of hypertension did not result in cognitive deterioration across the cohort of subjects (mean age 83 years) [23]. However, subjects with hypertension and cognitive executive dysfunction increasingly progressed to dementia (58\% in five years) compared with normotensives $(28 \%)$ but not in those with hypertension and memory dysfunction (74\% versus 67\%).

Our study extends the available literature on the role of hypertension and dementia in the very elderly but has several limitations. Information on hypertension and blood pressure medication was self-reported; we performed no blood pressure determinations. However, previous studies in our population and others support the reliability of selfreported health practices, drug usage, and medical history of major chronic disease $[8,9]$. Although changes over time in all potential risk factors may affect outcome, new cases of hypertension were reported in only a small minority of subjects. Additionally, the proportion of demented individuals 
is undoubtedly an underestimate of the true incidence, and we lacked clinical diagnoses of dementia based on standard criteria for many subjects. Subjects with dementia who had not been seen in person or hospitalized and were not reported as having dementia at the time of the followup surveys or on their death certificates were actually misclassified into the nondemented group. This has, with all likelihood, weakened the associations seen here. For these reasons our results are preliminary and incomplete. Furthermore, our subjects are from a select population-moderately affluent, highly educated, health conscious, and primarily Caucasian. Although this may limit the generalizability of our results, it reduces potential confounding by race, education, SES, and presumed access to health care. Nonetheless, unrecognized and uncontrolled confounders cannot be ruled out in this study or any observational study.

Clinical trials of antihypertensive medication in older subjects have also yielded inconsistent results (reviewed by [2-4]). Randomized controlled trials have demonstrated that blood pressure-reducing agents decrease the incidence of dementia in stroke patients (PROGRESS [24], HOPE [25]) and in older ( $\geq 60$ years) patients with isolated systolic hypertension (SYST-EUR) $[26,27]$, but this was not found in SHEP [28], SCOPE [29], and HYVET-COG [30]. These latter three included more elderly patients. The SHEP (Systolic Hypertension in the Elderly Programme) trial of 4736 patients (mean age 72 years) found a nonsignificant $16 \%$ reduction in dementia in treatment groups. The SCOPE (Study on Cognition and Prognosis in the Elderly) study of 4964 elderly (mean age 76 years) and HYVET-COG (Hypertension in the Very Elderly Trial-cognitive function assessment) of 3336 patients aged $\geq 80$ years found no effect on cognitive decline, Alzheimer's disease, or vascular dementia. Since different antihypertensive medications were used by our study subjects as well as in the clinical trials which looked for an effect of medication on dementia development, a specific class effect cannot be ruled out.

Others have detailed the possible mechanisms by which hypertension may increase risk of dementia (reviewed in [3, 4]). Hypertension may promote blood vessel wall thickening leading to arteriosclerosis and lipohyalinosis; cause stroke, focal ischemia, chronic hypoperfusion of the white matter, and white matter lesions; cause microcirculation disorders and endothelial dysfunction which may compromise the function of the blood brain barrier leading to increased vascular permeability and extravasation of protein into the cerebral parenchyma.

Although not establishing a cause and effect relationship between incident dementia and high blood pressure and its treatment, this large elderly cohort suggests an increased risk of dementia in the younger ( $<75$ years) men with untreated hypertension and with past use of hypertensive medication. This agrees with the findings of earlier studies showing an increased risk of dementia with higher measured blood pressure levels. In women the risk among current (at baseline) users of blood pressure medication, which was the strongest in the older age group (75+ years), highlights the need for careful monitoring of blood pressure in the elderly. Decline in blood pressure is common at ages above 75 years, and the Kungsholmen Project found low blood pressure to be associated with dementia risk ( $\mathrm{HR}=1.5,95 \%$ CI 1.0-2.1) [13]. Periods of hypotension, hypoperfusion and hypoxia observed in subjects on antihypertensives might contribute to cognitive decline via reduced cerebral blood flow, causing ischemic lesions in the brain.

\section{Conclusion}

Although treating hypertension has a clear effect on stroke, cardiovascular disease, and mortality, the effect of hypertension and its treatment on dementia is more complex. While previous studies have found midlife hypertension to be related to dementia, results for late-life hypertension and its treatment are inconsistent. Our study in older adults suggests that the effect varies not only with age (with a difference between those less than 75 years old and those $75+$ years old) but also with sex. Future studies examining the role of hypertension in older adults should perform sex-specific analyses.

\section{Acknowledgments}

This research was funded by Grants from the National Institutes of Health (R01CA32197 and R01AG21055), the Errol Carroll Trust Fund, Wyeth-Ayerst Laboratories.

\section{References}

[1] C. P. Ferri, M. Prince, C. Brayne et al., "Global prevalence of dementia: a Delphi consensus study," The Lancet, vol. 366, no. 9503, pp. 2112-2117, 2005.

[2] S. A. Ligthart, E. P. M. van Charante, W. A. van Gool, and E. Richard, "Treatment of cardiovascular risk factors to prevent cognitive decline and dementia: a systematic review," Vascular Health and Risk Management, vol. 6, no. 1, pp. 775-785, 2010.

[3] E. Duron and O. Hanon, "Vascular risk factors, cognitve decline, and dementia," Vascular Health and Risk Management, vol. 4, no. 2, pp. 363-381, 2008.

[4] S. P. Kennelly, B. A. Lawlor, and R. A. Kenny, "Blood pressure and dementia-a comprehensive review," Therapeutic Advances in Neurological Disorders, vol. 2, no. 4, pp. 241-260, 2009.

[5] M. M. Corrada, R. Brookmeyer, D. Berlau, A. Paganini-Hill, and C. H. Kawas, "Prevalence of dementia after age 90: results from The 90+ Study," Neurology, vol. 71, no. 5, pp. 337-343, 2008.

[6] A. Paganini-Hill, R. K. Ross, and B. E. Henderson, "Prevalence of chronic disease and health practices in a retirement community," Journal of Chronic Diseases, vol. 39, no. 9, pp. 699-707, 1986.

[7] A. Paganini-Hill, A. Chao, R. K. Ross, and B. E. Henderson, "Exercise and other factors in the prevention of hip fracture: the Leisure World Study," Epidemiology, vol. 2, no. 1, pp. 1625, 1991.

[8] A. Paganini-Hill and A. Chao, "Accuracy of recall of hip fracture, heart attack, and cancer: a comparison of postal survey data and medical records," American Journal of Epidemiology, vol. 138, no. 2, pp. 101-106, 1993. 
[9] A. Paganini-Hill and R. K. Ross, "Reliability of recall of drug usage and other health-related information," American Journal of Epidemiology, vol. 116, no. 1, pp. 114-122, 1982.

[10] G. M. Savva, S. B. Wharton, P. G. Ince, G. Forster, F. E. Matthews, and C. Brayne, "Age, neuropathology, and dementia," New England Journal of Medicine, vol. 360, no. 22, pp. 2302-2309, 2009.

[11] J. A. Schneider, Z. Arvanitakis, W. Bang, and D. A. Bennett, "Mixed brain pathologies account for most dementia cases in community-dwelling older persons," Neurology, vol. 69, no. 24, pp. 2197-2204, 2007.

[12] I. Skoog, B. Lernfelt, S. Landahl et al., "15-year longitudinal study of blood pressure and dementia," The Lancet, vol. 347, no. 9009, pp. 1141-1145, 1996.

[13] C. Qiu, E. von Strauss, J. Fastbom, B. Winblad, and L. Fratiglioni, "Low blood pressure and risk of dementia in the Kungsholmen Project: a 6-year follow-up study," Archives of Neurology, vol. 60, no. 2, pp. 223-228, 2003.

[14] T. Yoshitake, Y. Kiyohara, I. Kato et al., "Incidence and risk factors of vascular dementia and Alzheimer's disease in a defined elderly Japanese population: the Hisayama study," Neurology, vol. 45, no. 6, pp. 1161-1168, 1995.

[15] G. Li, I. C. Rhew, J. B. Shofer et al., "Age-varying association between blood pressure and risk of dementia in those aged 65 and older: a community-based prospective cohort study," Journal of the American Geriatrics Society, vol. 55, no. 8, pp. 1161-1167, 2007.

[16] D. B. Petitti, V. C. Crooks, J. G. Buckwalter, and V. Chiu, "Blood pressure levels before dementia," Archives of Neurology, vol. 62, no. 1, pp. 112-116, 2005.

[17] C. Brayne, C. Gill, F. A. Huppert et al., "Vascular risks and incident dementia: results from a cohort study of the very old," Dementia and Geriatric Cognitive Disorders, vol. 9, no. 3, pp. 175-180, 1998.

[18] L. H. Kuller, O. L. Lopez, A. Newman et al., "Risk factors for dementia in the Cardiovascular Health Cognition Study," Neuroepidemiology, vol. 22, no. 1, pp. 13-22, 2003.

[19] S. L. Tyas, J. Manfreda, L. A. Strain, and P. R. Montgomery, "Risk factors for Alzheimer's disease: a population-based, longitudinal study in Manitoda, Canada," International Journal of Epidemiology, vol. 30, no. 3, pp. 590-597, 2001.

[20] J. Lindsay, D. Laurin, R. Verreault et al., "Risk factors for Alzheimer's disease: a prospective analysis from the Canadian Study of Health and Aging," American Journal of Epidemiology, vol. 156, no. 5, pp. 445-453, 2002.

[21] A. R. Borenstein, Y. Wu, J. A. Mortimer et al., "Developmental and vascular risk factors for Alzheimer's disease," Neurobiology of Aging, vol. 26, no. 3, pp. 325-334, 2005.

[22] H. B. Posner, M.-X. Tang, J. Luchsinger, R. Lantigua, Y. Stern, and R. Mayeux, "The relationship of hypertension in the elderly to AD, vascular dementia, and cognitive function," Neurology, vol. 58, no. 8, pp. 1175-1181, 2002.

[23] S. Oveisgharan and V. Hachinski, "Hypertension, executive dysfunction, and progression to dementia: the Canadian Study of Health and Aging," Archives of Neurology, vol. 67, no. 2, pp. 187-192, 2010.

[24] C. Tzourio, C. Anderson, N. Chapman et al., "Effects of blood pressure lowering with perindopril and indapamide therapy on dementia and cognitive decline in patients with cerebrovascular disease," Archives of Internal Medicine, vol. 163, no. 9, pp. 1069-1075, 2003.

[25] J. Bosch, S. Yusuf, J. Pogue et al., "Use of ramipril in preventing stroke: double blind randomised trial," British Medical Journal, vol. 324, no. 7339, pp. 699-702, 2002.
[26] F. Forette, M. L. Seux, J. A. Staessen et al., "Prevention of dementia in randomised double-blind placebo-controlled Systolic Hypertension in Europe (Syst-Eur) trial," The Lancet, vol. 352, no. 9137, pp. 1347-1351, 1998.

[27] F. Forette, M. L. Seux, J. A. Staessen et al., "The prevention of dementia with antihypertensive treatment: new evidence from the Systolic Hypertension in Europe (Syst-Eur) study," Archives of Internal Medicine, vol. 162, no. 18, pp. 2046-2052, 2002.

[28] SHEP Cooperative Research Group, "Prevention of stroke by antihypertensive drug treatment in older persons with isolated systolic hypertension: final results of the Systolic Hypertension in the Elderly Program (SHEP)," Journal of the American Medical Association, vol. 265, no. 24, pp. 3255-3264, 1991.

[29] H. Lithell, L. Hansson, I. Skoog et al., "The Study on Cognition and Prognosis in the Elderly (SCOPE): principal results of a randomized double-blind intervention trial," Journal of Hypertension, vol. 21, no. 5, pp. 875-886, 2003.

[30] R. Peters, N. Beckett, F. Forette et al., "Incident dementia and blood pressure lowering in the Hypertension in the Very Elderly Trial Cognitive Function Assessment (HYVETCOG): a double-blind, placebo controlled trial," The Lancet Neurology, vol. 7, no. 8, pp. 683-689, 2008. 


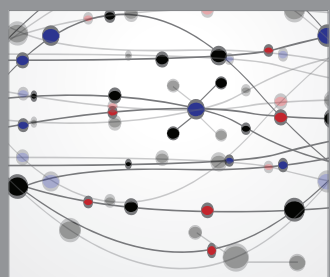

The Scientific World Journal
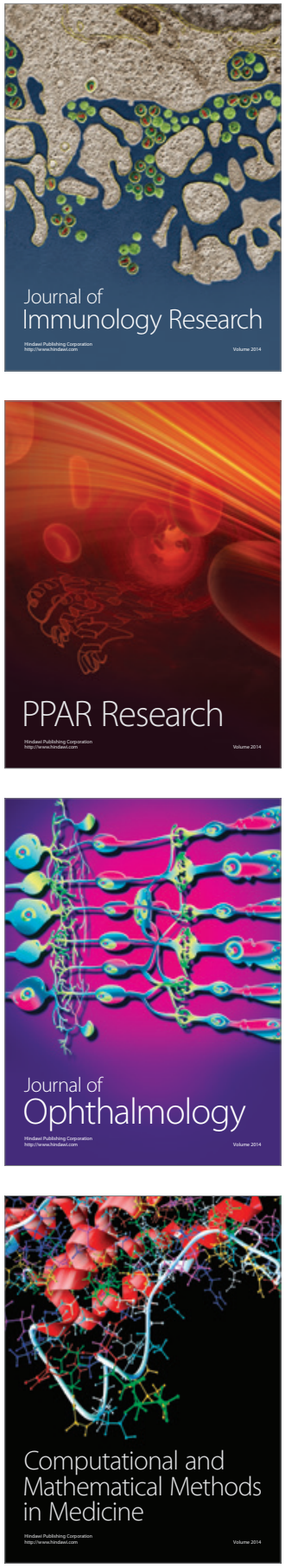

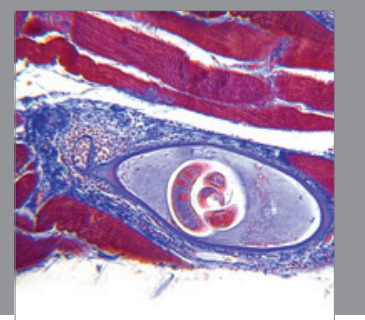

Gastroenterology

Research and Practice
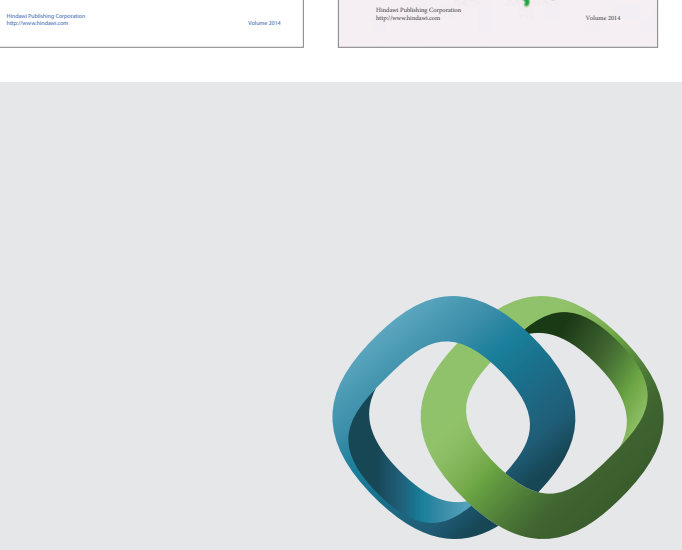

\section{Hindawi}

Submit your manuscripts at

http://www.hindawi.com
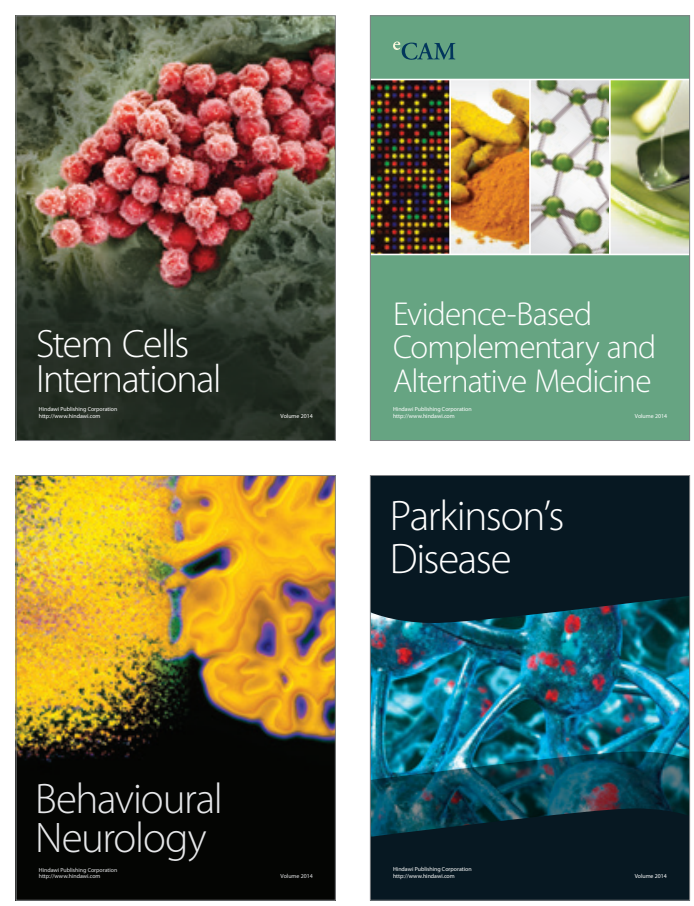

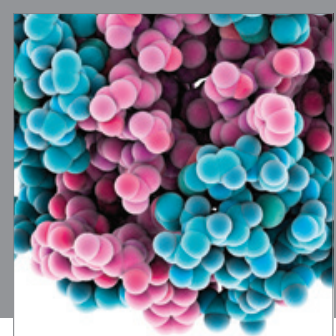

Journal of
Diabetes Research

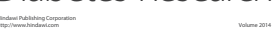

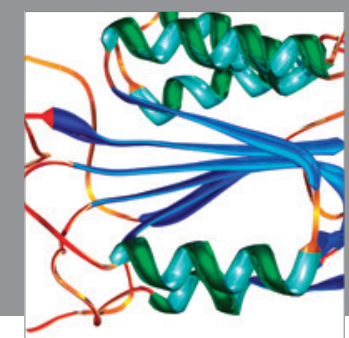

Disease Markers
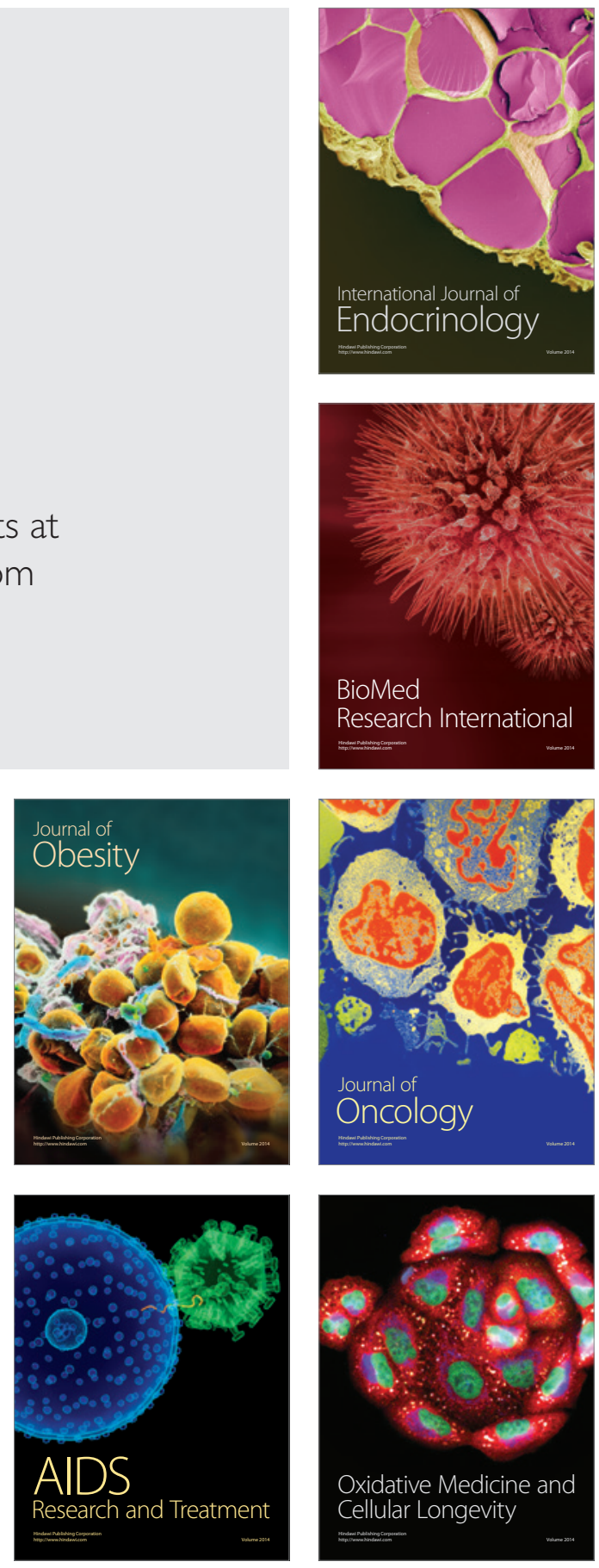